\title{
COBERTURA DE AVEIA E CALAGEM SOBRE AMENDOIM-BRAVO EM SEMEADURA DIRETA DE SOJA ${ }^{1}$
}

\author{
GUNTHER SEIFERT $^{2}$ e ELEMAR VOLL ${ }^{3}$
}

\section{RESUMO}

Este trabalho teve como objetivo avaliar o comportamento de Euphorbia heterophylla L., e o seu controle sob os efeitos de manejos com calcário e cobertura morta do solo com aveiapreta, em semeadura direta de soja. O ensaio foi instalado em Latossolo Roxo distrófico, na Fazenda Experimental da Embrapa Soja, em Warta (Londrina), PR, em 1997/98. O delineamento experimental usado foi em blocos ao acaso, no esquema fatorial $2 \times 2 \times 2$, com quatro repetições. Os tratamentos foram: 1. Calcário (com e sem), 2. Aveia (com e sem) e, 3. Controle herbicida (com e sem). Avaliações da evolução do banco de sementes e da flora emergente da espécie foram feitas em pré e pós-semeadura da soja. No período de corte da aveia até a fase de enchimento de vagem da soja (R5), nos manejos de calcário ou de aveia houve um decréscimo médio do banco de sementes no solo de $83,2 \%$ e, sem os manejos, um decréscimo de $91,9 \%$. As taxas de emergência em pré-semeadura da soja foram de $4,7 \%$, em média, semelhantes com ou sem calcário, porém maior na ausência de aveia, do que na presença; em póssemeadura, a taxa média foi de $12,6 \%$, não diferindo entre os manejos. Uma maior intensidade de infestação no manejo com aveia, sem controle, reduziu a produtividade da soja. A infestação foi superada no manejo de calcário, produzindo significativamente mais soja.

Palavras chave: Banco de sementes, Avena strigosa, leiteira, Euphorbia heterophylla.

\section{ABSTRACT \\ Effects of oats and liming of the development of wild poinsetia in no-till soybeans}

The objective of this study was to evaluate the behavior of wild poinsetia (Euphorbia heterophylla L.), and its control by soil liming and black oat cover crop management in no-till soybeans. One experiment was conducted on Latossolo Roxo dystrophic soil, at Embrapa Soja Experiment Station, at Warta, Londrina, PR, in 1997/98. The experimental design was a randomized complete block design, in a factorial $2 \times 2 \times 2$, with four replications. The treatments consisted of: 1. Liming (with and without), 2. Oat cover crop (with and without) and, 3. herbicide control (with and without).
Assessment of the weed seedbank evolution in time and of the emerging flora were made at preand post-emergence of soybean sowing. From the time oat was chopped until soybean pod filling stage (R5), there was a mean decrease of the seedbank by $83,2 \%$, under liming or oat cover management, and $91,9 \%$ where there was a no liming or oat cover. Emergence rate at pre-sowing soybean were of $4,7 \%$, as a mean, equal for liming or not, but higher for oat absence, as to presence; at post-sowing, mean emergence rate was of $12,6 \%$, with no differences between managements. A major weed

\footnotetext{
${ }^{1}$ Recebido para publicação em 11/05/99 e na forma revisada em 05/07/99. Trabalho de dissertação de Mestrado do $1^{\circ}$ autor apresentada à Universidade Estadual de Londrina

2 Aluno de Pós-Graduação, nível de Mestrado, da Universidade Estadual de Londrina. C.P. 2251, CEP: 86100-000, Londrina/PR.

${ }^{3}$ Pesquisador PhD, UEL/EMBRAPA/IAPAR. C.P 231, CEP: 86001-970, Londrina/PR.
} 
infestation in the oat management treatment, without control, reduced s oybean yield. The infestation was supressed by liming, producing significatively more.

Key words: Seedbank, Avena strigosa, liming, Euphorbia heterophylla.

\section{INTRODUÇÃO}

O Brasil se destaca como um dos principais países produtores de grãos de soja e maior exportador de farelo de soja do mundo. $\mathrm{O}$ estado do Paraná é um dos principais produtores de soja do País, sendo responsável por aproximadamente 2,77 milhões/ha de área plantada com uma produção de 7,06 milhões t/ano (97/98) com uma produtividade de $2.550 \mathrm{~kg} / \mathrm{ha}$, segundo a Conab/Didem/Geame (1998).

As plantas daninhas, possuem alta capacidade de competição em relação às espécies cultivadas e economicamente importantes. Esta capacidade de competição por luz, nutrientes e água ocasiona prejuízos à produção agrícola, reduzindo e diminuindo a qualidade dos produtos finais.

Uma das técnicas de produção utilizada é a semeadura direta, que consiste na movimentação mínima do solo e tem por finalidade conservar sua estrutura física, evitando a desestruturação, comum no sistema convencional pelas inúmeras operações de revolvimento. Por sua vez, na semeadura direta, a aveia é uma das culturas mais utilizadas no cultivo de inverno, que precede a cultura da soja em semeadura direta e serve para fornecer cobertura morta ao solo, melhorar as suas condições físicas, além de proporcionar efeitos alelopáticos para o controle das plantas daninhas.

Osman et al. (1991), observaram que coberturas vegetais podem reduzir a germinação e a emergência de espécies daninhas devido a fatores como água, luz, temperatura ou alelopatia. Almeida et al. 1985, observa que as principais culturas de inverno como: aveia, centeio, naboforrageiro e colza são as que, após a colheita, deixam o terreno com menor infestação de plantas daninhas. São também as que tem efeito mais prolongado sobre as plantas daninhas, especialmente a aveia, que aos 85 dias depois da formação da cobertura morta, ainda mantém o terreno com baixa infestação. Em semeadura direta a presença de biomassa de culturas anteriores, e os seus efeitos alelopáticos entre outros, tem sido muito importante em reduzir a intensidade de emergência de espécies daninhas (Liebl \& Worsham, 1983). Os sintomas dos efeitos alelopáticos mais citados na literatura, provocados pelas coberturas mortas nas culturas, são a redução de germinação, falta de vigor vegetativo ou morte das plântulas, amarelecimento ou clorose das folhas, redução do perfilhamento e atrofiamento ou deformação das raízes das plantas daninhas (Kimber, 1967, 1973; Norstadt \& McCalla, 1968 e McCalla \& Norstadt, 1974).

Alelopatia é um fator provocado pela introdução de substância químicas elaboradas pelas plantas que afetam elementos da comunidade. Nos trabalhos realizados por Almeida \& Rodrigues (1985), a cultura de inverno que nas condições edafoclimáticas do Paraná produz maior quantidade de biomassa seca é a aveia, em média $6.000 \mathrm{~kg} / \mathrm{ha}$. A aveia, centeio e demais cereais rebrotam, quando são cortados antes do estádio de grão leitoso, o que exige a sua eliminação por herbicidas para evitar a produção de semente. Aquelas que caem no chão por ocasião da colheita dão origem a tiguera. A aveia tem, além disso, o inconveniente de permanecer dormente no terreno, podendo infestar a cultura de inverno seguinte. Em testes de germinação de sementes de diversas espécies silvestres, Steinsiek et al. (1982) usaram o lixiviado de palha de trigo recém colhido, à concentração correspondente à de uma precipitação de $12,5 \mathrm{~mm}$ numa cobertura morta de $3.360 \mathrm{~kg} / \mathrm{ha}$, e observaram inibição, em ordem decrescente, das espécies: Ipomoea, Abutilon theopharasti, Sesbania exaltata, Senna obtusifolia e Echinochloa crusgalli. Os sintomas induzidos nestas espécies foram atrofia de crescimento, inibição de desenvolvimento das raízes primárias e incremento das secundárias, clorose, abscisão prematura das folhas, 
retardamento da maturação, deficiência de reprodução e inibição de germinação das sementes (Almeida, 1988).

Segundo Almeida \& Rodrigues (1985), o uso exclusivo destes produtos químicos alelopáticos traz problemas de substituição do complexo mato-florístico normal da região, por outro formado por espécies que lhes são resistentes, é o caso do leiteiro.

O leiteiro é uma das principais plantas daninhas da cultura da soja (Glycine max L.) no Brasil (Allem \& Irgang, 1975), largamente estudado por pesquisadores quanto ao seu aspecto botânico, distribuição e controle (Kissmann, 1980; Petrelli, 1983 e Lorenzi, 1991). Além de difícil controle, sua propagação é bastante intensa e com competição séria na soja. Segundo Burgeois (1990) a importância de fatores ecológicos tais como, tipo de solo, chuvas, altitude e fatores agronômicos como a idade da lavoura, uso de herbicidas, intensificação de cultivos, podem afetar a abundância das espécies e a evolução das populações no solo. Entre os fatores que determinam a germinação de Euphorbia heterophylla em laboratório, temperaturas alternadas de $25 / 30^{\circ} \mathrm{C}$, resultam em melhor germinação, enquanto a presença de luz não é fator limitante, e a viabilidade das sementes não é afetada pelo teor de umidade abaixo de $10 \%$ com temperaturas de $25^{\circ} \mathrm{C}$ (Bannon et al., 1978).

Cerdeira \& Voll (1980), conduziram experimentos em condições de casa-de-vegetação utilizando latossolo roxo distrófico, como substrato para enchimento de vasos, observaram que o leiteiro foi capaz de germinar a uma profundidade de até $12 \mathrm{~cm}$, num período de 4 a 18 dias. Na superfície do solo a emergência máxima de $48 \%$ foi atingida entre o $4^{\circ}$ e o $13^{\circ}$ dia, enquanto que a $12 \mathrm{~cm}$ o início da emergência se deu no $10^{\circ}$ dia encerrando no $18^{\circ}$ dia, quando emergiu apenas $12 \%$. Não foi avaliada a sobrevivência das sementes. A melhor temperatura de germinação variou entre $20-25^{\circ} \mathrm{C}$.

Machado Neto \& Pitelli

(1980) observaram em laboratório, em latossolo vermelho escuro, uma emergência maior de $80 \%$ nas profundidades de 2-10 $\mathrm{cm}$ e apenas $21 \%$ na superfície do solo. Esta redução na emergência seria devido a efeitos de ressecamento na superfície. Outros fatores como estresse hídrico, potenciais osmóticos, $\mathrm{pH}$, profundidade e espécies tem influência na qualidade de germinação das sementes.

Segundo Keeley \& Thullen (1989) a época de estabelecimento das espécies daninhas em relação a cultura é muito importante. As lavouras devem ser mantidas no limpo por períodos maiores do que os períodos de sobrevivência das espécies, para não causarem perdas de produção. A longevidade das sementes declina com o decorrer do tempo, profundidade, irrigação e tipo de solo de diferentes locais (Dawson \& Burns, 1975).

Segundo Panetta et al. (1988) a sobrevivência de sementes no tempo declina também com o uso de herbicidas. No entanto, as que escapam podem produzir um grande número de sementes. Para fins agrícolas, a determinação do banco de sementes é voltada aos estudos relativos às plantas daninhas. A sobrevivência de plantas daninhas é função da intensidade da germinação, da emergência e da morte das espécies na sua interação com o meio ambiente (Leguizamón, 1986).

Existem diversas citações a respeito de produtos químicos que colocados no solo exercem alguma influência na viabilidade, vigor e quebra de dormência das sementes. Turkiewicz (1976), ao trabalhar com calcário, concluiu que além de ser corretivo de solo, fornece nutrientes às plantas $\mathrm{e}$ observou que este favorece a obtenção de sementes de soja com maior viabilidade e vigor. $\mathrm{O}$ pH do solo é um aspecto extremamente importante a ser considerado no estudo de potenciais tratamentos químicos na superação de dormência de sementes.

Buchanan et al. (1975) nos EUA, estudaram a resposta das plantas daninhas ao $\mathrm{pH}$ do solo entre os níveis de 4,7 a 6,3. Verificaram que as espécies que se mostraram altamente tolerantes ao $\mathrm{pH}$ baixo, médio e alto. 
Este trabalho teve por finalidade avaliar o comportamento de leiteiro (Euphorbia heterophylla L.), e o seu controle em semeadura direta da soja, sob a aplicação de calcário e cobertura de aveia no solo.

\section{MATERIAL E MÉTODOS}

O experimento de campo foi conduzido nas dependências da Fazenda Experimental da Embrapa Soja, Londrina PR, situada a $23^{\circ} 23^{\prime}$ de latitude sul e $51^{\circ} 11^{\prime}$ de longitude WGr. em 1997/98, em latossolo roxo distrófico, com $75 \%$ de argila e 2,7\% de matéria orgânica. As características químicas do solo foram: $\mathrm{pH}\left(\mathrm{CaCl}_{2}\right)$ $=5,17, \mathrm{Al}=0,00 \mathrm{me}, \mathrm{K}=0,66 \mathrm{me}, \mathrm{Ca}^{+2}=5,41 \mathrm{me}$, e $\mathrm{Mg}^{+2}=2,55 \mathrm{cmol}_{\mathrm{c}} / \mathrm{dm}^{3}$ de solo e $\mathrm{P}=13,9$ $\mathrm{mg} / \mathrm{dm}^{3}$. O clima da região segundo a classificação de Köppen, pertence ao tipo Cfa, ou seja, clima subtropical úmido, com chuvas em todas as estações, podendo ocorrer seca no período de inverno. A temperatura média anual está em torno de $20,7^{\circ} \mathrm{C}$ e a precipitação de $1615 \mathrm{~mm}$ (Corrêa et al. 1982).

Os fatores e níveis (tratamentos) no experimento foram:1) áreas tratadas com calcário e sem calcário; 2) áreas com plantio de aveia e sem plantio de aveia e 3) áreas com controle e área sem controle de leiteiro. $O$ delineamento experimental usado foi em blocos ao acaso, com 8 tratamentos, em esquema fatorial de $2 \times 2 \times 2$ e quatro repetições. As parcelas mediram $6 \mathrm{~m} \times 6 \mathrm{~m}$, com $25 \mathrm{~m}^{2}$ de área útil e com área total $864 \mathrm{~m}^{2}$, sendo a área útil de $800 \mathrm{~m}^{2}$.

$\mathrm{O}$ experimento foi instalado em maio de 1997, em local com alta infestação de leiteiro, além de outras espécies daninhas como: Bidens pilosa, Brachiaria plantaginea, Ammaranthus spp., Commelinea spp.

Em 14.05.97, foi semeada aveia-preta, com a semeadeira "Semeato SHM-15" com 13 linhas, num espaçamento entre linhas de $0,30 \mathrm{~m}$ com 13 linhas por parcela, com a distribuição de 40 a 50 sementes $/ \mathrm{m}$, resultando numa média de 32 a 40 plantas $/ \mathrm{m}$. Por ocasião da semeadura da aveia, foi feita a adubação para a cultura de
$200 \mathrm{~kg} / \mathrm{ha}$ da fórmula 4-30-20. Após 3 meses do plantio, na fase de espigamento, foi feita a avaliação da produção de massa verde por amostragem. Para isso, foi usado um quadro com $0,5 \times 0,5 \mathrm{~m}$. A amostragem consistiu em 4 áreas (ou cortes) de $0,25 \mathrm{~m}^{2}$, casualizadas dentro das parcelas do tratamento, perfazendo um total de $1 \mathrm{~m}^{2}$. Foi determinado o peso da matéria verde e, em seguida, foi colocado para secagem em estufa de ventilação forçada durante 72 horas a uma temperatura de $60^{\circ} \mathrm{C}$. A quantidade média de matéria seca obtida foi de $6.000 \mathrm{~kg} / \mathrm{ha}$.

Antes da aveia atingir o estádio de amadurecimento das espigas foi efetuado o corte, por meio do "Triton 2300", operação que triturou as plantas de aveia em pedaços não maiores que $5 \mathrm{~cm}$. O espalhamento foi feito uniformemente nas parcelas. A data do corte da aveia foi 27/08/97.

O manejo para eliminação das plantas daninhas infestantes, nos tratamentos sem aveia, foi realizado em 20/08/97, através da aplicação do herbicida glyphosate na dose de $760 \mathrm{~g}$ i.a./ha. mais $600 \mathrm{~g}$ i.a /ha de 2,4-D, com um volume de 200 litros de calda por hectare. Para isso, foi utilizado pulverizador tratorizado "Jacto PJ600" com barras de 12 metros, bicos em leque da série Teejet 110.03, distanciados em $50 \mathrm{~cm}$ numa altura de $40 \mathrm{~cm}$ do alvo, com pressão de $200 \mathrm{Kpa}$. A aplicação foi feita com ausência de ventos, céu nublado, temperatura de $22^{\circ} \mathrm{C}$, umidade relativa $56 \%$. O solo permaneceu em descanso até a época da semeadura da soja. Em 02/05/96 foi realizada a primeira amostragem de solo para análise química, a uma profundidade de $10 \mathrm{~cm}$, utilizando um trado tubular. Os resultados indicaram $\mathrm{pH} 4,8$ e Al $0,19 \%$. Baseado nestes resultados, através do método $\mathrm{V}(\%)$, para saturação de bases de $70 \%$, foi aplicado $2000 \mathrm{~kg} / \mathrm{ha}$ de calcário, incorporado com grade niveladora. Em 22/08/97 foi realizada a segunda amostragem para análise química do solo, coletando oito sub-amostras uma para cada parcela do experimento, que depois de homogeneizada em uma única amostra, foi enviada ao laboratório de solo da Embrapa. $\mathrm{O}$ resultado da análise apresentou pH de 5,17 $\left(\mathrm{CaCl}_{2}\right)$ e $\mathrm{Al}=0,0$. Baseado nestes resultados através do método $\mathrm{V}(\%)$, para 
saturação de bases de 70\%, chegou-se a necessidade de $3.000 \mathrm{~kg} / \mathrm{ha}$ de calcário. Foi então aplicado o calcário dolomítico, $100 \%$ de PRNT, espalhando-o na superfície do solo, mas não incorporando.

O manejo para eliminação das plantas daninhas presentes na véspera do plantio da soja, em todos os tratamentos, foi realizado em 6.11.97, com o herbicida glyphosate, na dose de $540 \mathrm{~g} \mathrm{i.a/ha,} \mathrm{mais} 600 \mathrm{~g}$ i.a/ha de 2,4-D, com pulverizador tratorizado "Jacto PJ600" com barras 12 metros, bicos em leque da série Teejet 110.03, distanciados em $50 \mathrm{~cm}$ um do outro aplicando uma faixa de $12 \mathrm{~m}$ de largura, numa altura de $40 \mathrm{~cm}$ do alvo e velocidade de $1,0 \mathrm{~m} / \mathrm{s}$, um volume de 200 litros de calda por hectare. A semeadura da soja cultivar BR-37, foi realizada no dia 21.11.97, com semeadura/adubadeira "Semeato" de 7 linhas, espaçadas de $50 \mathrm{~cm}$ uma da outra, regulada para distribuir 20 a 25 sementes por metro linear, e aplicar $250 \mathrm{~kg} / \mathrm{ha}$ de adubo da fórmula 00-30-20 na linha no lado e abaixo das sementes. As sementes de soja foram inoculadas com Bradyrhizobium japonicum na dose de $250 \mathrm{~g}$ por $50 \mathrm{~kg}$ de sementes. Realizou-se a adubação na cultura com $250 \mathrm{~kg} / \mathrm{ha}$ da fórmula 0-30-20. Logo após a semeadura da soja foi realizada uma aplicação do herbicida paraquat na dose de 300 g.i a /ha, em toda área do experimento, para eliminação da planta daninha trapoeraba, recém emergida. Para isto foi utilizado um pulverizador costal de precisão propelido a $\mathrm{CO}_{2}$, acoplado com barra de 2,0 metros de largura, contendo 4 bicos leque da série Teejet 110-03 distanciados $50 \mathrm{~cm}$ um do outro, que produziram um volume de calda de 200 1/ha.

Um levantamento inicial do banco de sementes no solo foi feito em 06/08/97. Levantamentos seguintes de plantas emergentes e do banco de sementes foram realizados em três épocas, sendo a primeira feita em 28/10/97, antes da semeadura da soja (pré-semeadura); o segundo foi realizado em 22/12/97, após a emergência da soja, com a finalidade de avaliar o potencial de leiteiro emergido, e para obter a estimativa do número de sementes existentes, antes da realização do manejo das plantas daninhas, quando o soja atingiu o estádio de $3^{\mathrm{a}}$ folha trifoliada; e a terceira em 17/02/98, no estádio (R5) da soja. Para o controle das plantas daninhas, após emergência da soja, visando eliminação total das mesmas, foi utilizado o herbicida imazethapyr na dose de 100 g.i.a/ha; enquanto nas parcelas nas quais desejava-se a presença do leiteiro somente, foi utilizado o herbicida bentazon na dose de 720 g.i.a/ha para eliminação das demais plantas dicotiledôneas. Para isso foi utilizado um pulverizador costal de precisão, com as mesmas características já mencionadas. As plantas daninhas presentes foram: Bidens pilosa, Commelina benghalensis, Amaranthus sp., Ipomoea aristolochiaefolia e Sida rhombifolia, que se encontravam em estádio de 2 a 3 pares de folhas.

Para acompanhar a evolução da emergência do leiteiro nas diferentes épocas, isto é, pré-plantio da soja, pós-semeadura (V3) e enchimento de vagens (R5), foram contados o número de indivíduos de leiteiro que emergiram em cada tratamento. Para isso, foram amostradas na parcelas dois pontos pré-fixados, utilizando uma armação de ferro de 1,0 x 1,0 = $1 \mathrm{~m}^{2}$, como delimitador de área amostrada. Baseado no levantamento inicial do banco de sementes (de cerca de 1087 sementes $/ \mathrm{m}^{2}$ ), determinado em 06/08/97, foram estabelecidas as taxas de emergência de leiteiro dos períodos de pré e póssemeadura da soja. As amostras de solo seguintes para avaliação do banco de sementes foram realizadas concomitantemente às avaliações de emergência da E. heterophylla.

Através de um trado tubular de $5 \mathrm{~cm}$ de diâmetro foram coletadas dez amostras de solo em cada parcela, no sentido diagonal da esquerda para direita, numa profundidade de $0-10 \mathrm{~cm}$. A área coletada corresponde a $1 / 50$ de um metro quadrado amostrado. As amostras foram secadas ao ar, a fim de evitar a germinação das sementes. Posteriormente, foram lavadas sob uma forte ducha de água, numa peneira de latão $(20 \mathrm{~cm}$ de diâmetro x $8 \mathrm{~cm}$ de borda), com malha inóx de $0,5 \mathrm{~mm}$, para eliminar a fração argilosa do solo. Após uma breve secagem à sombra, a porção 
remanescente na peneira foi flotada para a separação das sementes. A flotação consistiu no uso de uma solução saturada de $\mathrm{CaCl}_{2} 2 \mathrm{H}_{2} \mathrm{O}$, (cloreto de cálcio dihidratado), numa densidade de $1,40 \mathrm{~g} / \mathrm{cm}^{3}$ a $1,42 \mathrm{~g} / \mathrm{cm}^{3}$, o que permitiu a flutuação na superfície e separação das sementes de leiteiro menos densas que a solução.

Após secagem à sombra sobre papeltoalha e ventilação, para retirada de resíduos vegetais mais leves que as sementes de Euphorbia, as sementes de leiteiro foram identificadas e contadas com auxílio de uma lupa comum, separadas com uma pinça, usada com certa pressão, para identificar as sementes consideradas viáveis.

Foi determinada a produtividade das parcelas utilizando-se colhedoura mecânica de 3 linhas, marca "Wintersteiger Alita" determinandose produtividade da cultura por área útil de parcela, pesando-se os grãos em balança graduada. Os valores foram transformados em $\mathrm{kg} / \mathrm{ha}$ a $13 \%$ de umidade, utilizando-se a fórmula abaixo:

$(\mathrm{kg} / \mathrm{ha} 13 \%$ de umidade $)=\left(\mathrm{pp}^{*}(100-\right.$ up)*ap)/((100-13\% u $\left.)^{*} 10000\right)$, em que: pp = peso parcela; up = umidade de grão da parcela; ap = área da parcela; $\mathrm{u}=$ umidade.

O teor de umidade dos grãos de soja foi determinado num equipamento da marca "Burrows" (digital moisture computer 700).

Análises de variância do esquema fatorial foram feitas. O teste de comparações múltiplas dos efeitos médios dos tratamentos aplicados foi de Tukey $(\mathrm{P} \leq 0,05)$.

\section{RESULTADOS E DISCUSSÃO}

\section{1) Avaliação de efeitos sobre o banco de sementes}

\section{Avaliação de efeitos da aveia}

Na Tabela 1, são apresentados os números e evolução do banco de sementes de leiteiro ( $E$. heterophylla) nos tratamentos com e sem cobertura de aveia, no período anterior e posterior a semeadura da soja, realizada em 23/11/97. As avaliações após a semeadura da soja foram realizadas quando a mesma se encontrava em estágio de $3^{\circ}$ trifólio (V3) e no enchimento de vagens (R5). Pode-se verificar que o banco de sementes foi decrescente no período, em ambos os tratamentos. A partir de um banco de sementes inicial levantado, com quantidades semelhantes nos dois tratamentos, observa-se que não houve diferença significativa entre os tratamentos, no mês de outubro (pre-semeadura da soja), e sim, somente nos meses de dezembro e fevereiro, após a emergência da soja, em que o banco de sementes no tratamento sem aveia foi significativamente menor. Este menor banco de sementes, em relação ao tratamento com cobertura de aveia, possivelmente, está associado aos efeitos de maior temperatura e luminosidade incidente em solo descoberto, quebrando a dormência da semente.

TABELA 1. Quantidade de sementes de leiteiro no solo, nos tratamentos com e sem aveia, no período de agosto a dezembro/97 e fevereiro/98, em Londrina/PR. Embrapa Soja, 1998.

\begin{tabular}{ccccc}
\hline & \multicolumn{4}{c}{ Número de sementes $/ \mathrm{m}^{2}$} \\
\cline { 2 - 5 } Tratamento & \multicolumn{2}{c}{ Antes da semeadura } & \multicolumn{2}{c}{ Após semeadura } \\
\cline { 2 - 5 } & $06 / \mathrm{ago} / 97$ & $28 /$ out $/ 97$ & $22 / \mathrm{dez} / 97(\mathrm{~V} 3)$ & $17 / \mathrm{fev} / 98(\mathrm{R} 5)$ \\
\hline Com aveia & 1087,0 & $680,5 \mathrm{a}^{1^{\prime}}$ & $562,5 \mathrm{a}^{1 /}$ & $181.2 \mathrm{a}^{1 /}$ \\
Sem aveia & 1005,0 & $475,0 \mathrm{a}$ & $206,2 \mathrm{~b}$ & $81.2 \mathrm{~b}$ \\
\hline CV $(\%)$ & & 55,19 & 39,9 & 87.4 \\
F.05 & & 1,66 & 21,4 & $6 ; 01$ \\
P(F) & & 0,23 & 0,0015 & 0,0212 \\
\hline
\end{tabular}

1/ Médias seguidas de mesmas letras minúsculas na vertical não diferem significativamente entre si pelo teste de Tukey (P $\leq 0,05)$. 
Sob controle da reinfestação, uma estimativa do decréscimo anual do banco de sementes de leiteiro de $87,5 \%$, na média dos manejos, a sua sobrevivência estimada no solo seria de cerca de quatro anos. Robert \& Feast (1972), observaram um período de sobrevivência de 5 anos para a espécie $E$. helioscopica.

Segundo Parker et al. (1989), o decréscimo de bancos de sementes no solo varia em função da espécie, dormência, condições ambientais, presença de predadores e microrganismos. A dinâmica de bancos de sementes apresenta distintos padrões entre espécies de uma mesma comunidade e entre comunidades. Geralmente, a principal forma de decréscimo é através da germinação.

Probert et al. (1985) também observaram em experimentos conduzidos a campo, que as condições de temperatura em que a planta mãe de leiteiro foi submetida durante o desenvolvimento das sementes, podem exercer considerável influência nas respostas quantitativas de germinação na luz e em temperaturas alternadas. Além dos fatores ambientais, a genética de uma espécie qualquer determina o grau de dormência de sua semente (Chancellor, 1982). De maneira que, o conhecimento dos fatores que influenciam o estado de dormência do banco de sementes no solo tem sido considerado com um meio de predizer futuros problemas com plantas daninhas em culturas (Taylorson, 1985).

No presente caso, foi observado que a cobertura do solo com aveia semeada no inverno, seguida pela semeadura direta da soja, favorece a sobrevivência de um banco de sementes por mais tempo, em relação a um solo descoberto. Entretanto, sabe-se que a cobertura morta que se encontra na superfície do solo reduz a evaporação e conserva a umidade do solo, favorecendo a germinação de algumas espécies, mas dificultando a de outras (Vieira, 1981), sendo isto também confirmado por Almeida (1988).

\section{Avaliação de efeitos da calagem}

Na Tabela 2, observa-se que a evolução do banco de sementes de leiteiro sob efeito dos tratamentos de calcário, no decorrer do tempo, também foi decrescente, com maior intensidade na ausência de calcário, sobretudo em fevereiro, assim como na presença de aveia, ou seja, o cultivo da aveia e ou adição do calcário produziram resultados semelhantes. Partindo de densidades iniciais de sementes por área semelhantes, talvez o resultado final obtido seja devido ao maior desenvolvimento da soja proporcionado pela presença de calcário, em conseqüência menor germinação devido a dormência das sementes. Segundo Carmona (1992) a taxa de decréscimo está diretamente relacionada a longevidade e dormência das sementes, pois a dormência distribui a germinação ao longo do tempo, garantindo o potencial de regeneração do banco de sementes mesmo em condições ambientais adversas à sobrevivência da espécie e de perturbação contínua do solo para fins de cultivo.

\section{2) Avaliação da flora emergente}

\section{Avaliação de efeitos da aveia}

Na Tabela 3, na mesma seqüência de datas do banco de sementes, observa-se que, no tratamento com aveia, as emergências de leiteiro não apresentaram diferenças significativas entre as três épocas de determinação, no entanto, na ausência de aveia, exceto na primeira data, foram decrescentes e inferiores em número.

O procedimento de rolagem da aveia, bem como o manejo químico na ausência de aveia, resultaram em igual intensidade de plantas emergidas em outubro, favorecido por melhores condições de temperatura, talvez, na ausência de cobertura do solo pela aveia. Por sua vez, a maior emergência com aveia, posteriormente, devese a um banco de sementes maior, remanescente do período anterior, sem efeitos diferenciais dos tratamentos, após a semeadura. 
TABELA 2. Quantidade de sementes de leiteiro no solo, nos tratamentos com e sem calcário, no período de agosto97 a fevereiro/98, em Londrina/PR.

\begin{tabular}{|c|c|c|c|c|}
\hline \multirow{3}{*}{ Tratamento } & \multicolumn{4}{|c|}{ Número de sementes $/ \mathrm{m}^{2}$} \\
\hline & \multicolumn{2}{|c|}{ Antes da semeadura } & \multicolumn{2}{|c|}{ Após semeadura } \\
\hline & 06/ago/97 & 28/out/97 & 22/dez/97 (V3) & 17/fev/98 (R5) \\
\hline Com calcário & 1062,0 & $543,0 \mathrm{a}^{1 /}$ & $440,0 \mathrm{a}$ & $180,2 \mathrm{a}$ \\
\hline Sem calcário & 1012,0 & $611,0 \mathrm{a}$ & $328,0 \mathrm{a}$ & $82,2 \mathrm{~b}$ \\
\hline $\mathrm{CV}(\%)$ & & 55,19 & 39,9 & 87,4 \\
\hline F.05 & & 1,66 & 2,14 & 6,01 \\
\hline $\mathrm{P}(\mathrm{F})$ & & 0,23 & 0,175 & 0,0212 \\
\hline
\end{tabular}

1/ Médias seguidas de mesmas letras minúsculas na vertical não diferem significativamente entre si pelo teste de Tukey $(\mathrm{P} \leq 0,05)$.

TABELA 3. Intensidade de emergência de plantas de leiteiro nos tratamentos com e sem aveia, nos meses de outubro e dezembro/97 e fevereiro/98, em Londrina/PR.

\begin{tabular}{cccc}
\hline \multirow{2}{*}{ Tratamento } & \multicolumn{3}{c}{ Número de plantas $/ \mathrm{m}^{2}$} \\
\cline { 2 - 4 } & $28 /$ out/97 & $22 / \mathrm{dez} / 97$ & $17 / \mathrm{fev} / 98$ \\
\hline Com aveia & $28,6 \mathrm{aA}$ & $37,0 \mathrm{Aa}$ & $33,6 \mathrm{aA}$ \\
Sem aveia & $28,1 \mathrm{aA}$ & $15,0 \mathrm{bB}$ & $13,4 \mathrm{bB}$ \\
\hline CV $(\%)$ & 26,7 & 41,7 & 17,0 \\
F.05 & 0,013 & 16,2 & 240,01 \\
P(F) & 0,908 & 0,0033 & 0,0001 \\
\hline
\end{tabular}

T/Médias seguidas de mesmas letras minúsculas na vertical e, maiúsculas na horizontal, não diferem significativamente entre si pelo teste de Tukey $(\mathrm{P} \leq 0,05)$.

- Semeadura de soja em 21/11/97.

A avaliação de fevereiro representou o acréscimo de novas plantas de leiteiro emergentes, bem como a sua mortalidade, em função da competição com a cultura. Purvis et al. (1985) estudaram efeito de coberturas mortas de sorgo, girassol, trigo e ervilha, na germinação e desenvolvimento de plantas daninhas, tendo verificado que todas elas e em especial o trigo e ervilha, incrementaram a germinação e crescimento de Avena fatua e A. sterilis. No entanto, as restantes espécies presentes no terreno foram inibidas pelos resíduos dessas culturas, sendo a extenção da inibição dependente do tipo de resíduo.

\section{Avaliação de efeitos da calagem}

$\mathrm{Na}$ Tabela 4, observa-se que, no tratamento sem calcário, as emergências de leiteiro não apresentaram diferenças significativas entre as três épocas de determinação, porém com calcário, na última data, a quantidade de plantas foi menor, 
podendo ter ocorrido maior mortalidade de plantas. Supõe-se que as plantas emergidas tenderam a ser em menor número na presença de calcário, desfavorecidas pela maior competição da cultura da soja. Turkiewicz (1976), ao trabalhar com calcário, concluiu que além de ser corretivo de solo, fornece nutrientes às plantas e observou que este favorece a germinação e o vigor de sementes de soja obtidas. Sabe-se também, que plantas cultivadas são melhoradas para darem altas respostas à aplicação de nutrientes, sendo as espécies daninhas menos responsivas.

TABELA 4. Intensidade de emergência de plantas de leiteiro nos tratamentos com e sem calcário, nos meses de outubro e dezembro/97 e fevereiro/98, em Londrina, PR Embrapa-soja.1998.

\begin{tabular}{cccc}
\hline \multirow{2}{*}{ Tratamento } & \multicolumn{3}{c}{ Número de plantas $/ \mathrm{m}^{2}$} \\
\cline { 2 - 4 } & $28 /$ out/97 & $22 / \mathrm{dez} / 97$ & $17 / \mathrm{fev} / 98$ \\
\hline Com calcário & $22,3 \mathrm{bA}$ & $24,7 \mathrm{aA}$ & $17,6 \mathrm{bB}$ \\
Sem calcário & $34,4 \mathrm{aA}$ & $27,8 \mathrm{aA}$ & $29,4 \mathrm{aA}$ \\
\hline CV $(\%)=$ & 26,7 & 41,7 & 17,0 \\
$\mathrm{~F} .05=$ & 0,013 & 16,2 & 240,01 \\
$\mathrm{P}(\mathrm{F})=$ & 0,908 & 0,00328 & 0,0001 \\
\hline
\end{tabular}

${ }^{1}$ /Médias seguidas de mesmas letras minúsculas, na vertical, e maiúsculas, na horizontal, não diferem significativamente entre si pelo teste de Tukey $(\mathrm{P} \leq 0,05)$.

\section{3) Efeitos sobre a taxa de emergência}

Na Tabela 5, observa-se que as taxas de emergência, resultantes da relação entre as plantas emergidas e o banco de sementes determinado anteriormente (06/08/97), não presentaram diferenças significativas na presença ou ausência de calcário nos períodos de pré e pós-semeadura da soja. No entanto, no período de enchimento de vagens, ocorreu maior taxa de emergência na ausência de calcário do que na presença desta. Os dados indicam um incremento de plântulas emergentes na ausência de calcário, ocorrido após a avaliação de dezembro. Por outro lado, poderia ocorrer uma maior mortalidade de plântulas, resultante da maior competição com a cultura, favorecida pela aplicação de calcário.

As taxas de emergência resultantes da presença ou ausência de aveia, apresentaram diferenças significativas nos períodos de présemeadura da soja, sendo maior a taxa de emergência na ausência de aveia, que apresentou menor banco de sementes no solo e também, menor dormência. Não houve diferenças significativas para os tratamentos de aveia no período inicial de pós-semeadura da soja e de enchimento de vagens.

As taxas de emergência em pré-semeadura da soja foram de $4,7 \%$, em média, semelhantes para calcário, porém maiores na ausência de aveia; em pós-semeadura, a taxa média foi de $12,6 \%$, enquanto que, por ocasião do enchimento das vagens de soja (estágio R5) os dados não mostram evolução da emergência no tratamento com calcário.

Taxas de emergência relatadas em semeaduras de vaso para leiteiro, em laboratório, variaram entre 12 e $48 \%$ (Cerdeira e Voll, 1980), 20 e $81 \%$ (Machado Neto \& Pitelli, 1980).

\section{4) Efeitos da competição sobre a produção de soja}

Pode-se observar na Figura 1, o efeito isolado de cada tratamento de manejo, sem interação de fatores. Houve uma tendência a maior 
produção de soja nos tratamentos com calcário, após o pousio. A produção, no manejo precedido pela aveia, equivaleu-se à testemunha com controle. No entanto, na presença da infestação de leiteiro de 79,1 plantas $/ \mathrm{m}^{2}$, a produção foi significativamente menor, equivalendo-se a produção sem controle da testemunha, precedida pelo pousio, e com 31 plantas $/ \mathrm{m}^{2}$.

TABELA 5. Taxas de emergência de leiteiro nos períodos de pré e pós-semeadura da soja, nos tratamentos de calcário e aveia, na Embrapa-soja Londrina, PR 1997/98.

\begin{tabular}{|c|c|c|c|}
\hline \multirow[b]{2}{*}{ Tratamento } & \multicolumn{3}{|c|}{ Emergência de leiteiro (\%) } \\
\hline & $\begin{array}{l}\text { Pré-semeadura } \\
\text { (outubro) }\end{array}$ & $\begin{array}{c}\text { Pós-semeadura } \\
\text { (dezembro) }\end{array}$ & $\begin{array}{c}\text { Enchimento de vagens } \\
\text { (fevereiro) }\end{array}$ \\
\hline \multicolumn{4}{|l|}{ Calcário } \\
\hline Com & $4,4 \mathrm{a}$ & $11,0 \mathrm{a}$ & $9,9 \mathrm{~b}$ \\
\hline Sem & $5,1 \mathrm{a}$ & $14,2 \mathrm{a}$ & $26,3 \mathrm{a}$ \\
\hline \multicolumn{4}{|l|}{ Aveia } \\
\hline Com & $2,6 \mathrm{~b}$ & $13,4 \mathrm{a}$ & $20,2 \mathrm{a}$ \\
\hline Sem & $6,8 \mathrm{a}$ & $11,9 \mathrm{a}$ & $16,0 \mathrm{a}$ \\
\hline $\mathrm{CV}(\%)$ & 79,4 & 66,5 & 55,5 \\
\hline Média geral & 4,7 & 12,6 & 18,1 \\
\hline
\end{tabular}

1/Médias de cada fator seguidas de mesmas letras minúsculas, na vertical, não diferem significativamente entre si pelo teste de Tukey ( $\mathrm{P} \leq 0,05)$.

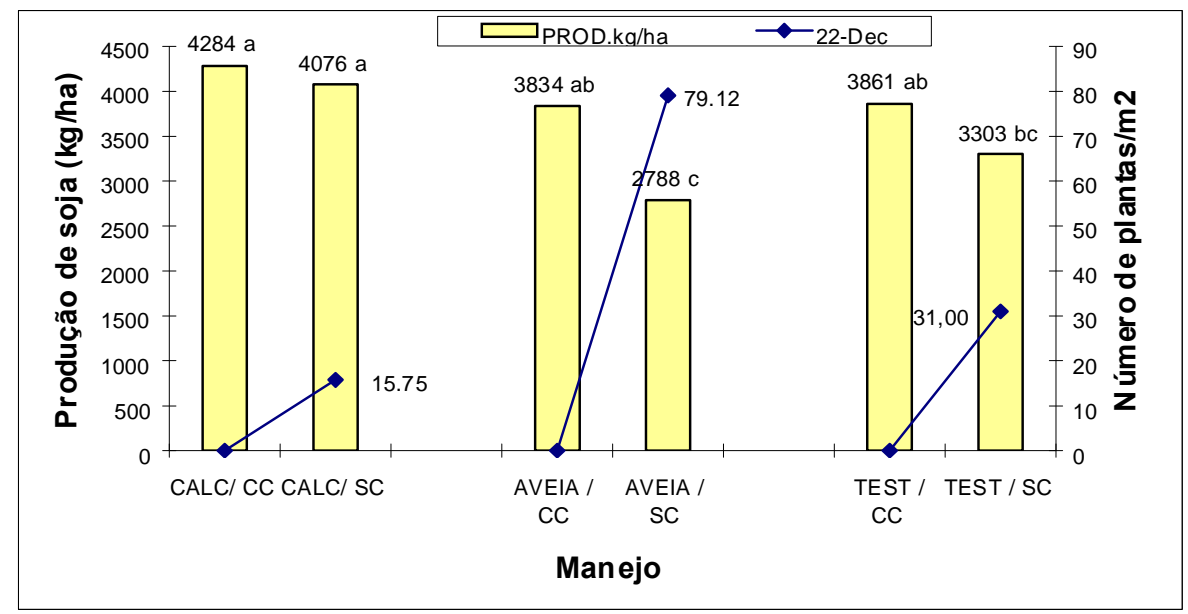

FIGURA 1. Produção de soja e número de plantas de leiteiro (em 22/12/97), nos de manejo de pousiocalcário (CALC) , aveia (AVEIA) e pousio-testemunha (TEST), com e sem controle (CC; SC), em Londrina, PR. Embrapa-soja 1997/98. (Médias acompanhadas pelas mesmas letras, não diferem entre si pelo teste de Tukey $\mathrm{P} \leq 0,05$ ). 
Transformando-se as médias de produção em porcentagem da testemunha, excluídos os dados de calcário, e estabelecendo-se uma relação com o número de plantas de leiteiro, pode-se descrever a seguinte equação de regressão linear: $\mathrm{Y}=98,5-0,3388 \mathrm{X}$, com $^{2}=0,97$, onde $\mathrm{Y}=\%$ de perda estimada de produção, e $\mathrm{X}=$ número de plantas de leiteiro $/ \mathrm{m}^{2}$. O ajuste $\left(\mathrm{r}^{2}\right)$ foi muito bom, indicando uma boa associação entre produção e plantas de leiteiro em competição. De modo geral, sob altos níveis de infestação (79 plantas $\left./ \mathrm{m}^{2}\right)$, poderia ocorrer, além da competição com a cultura (interespecífica) a competição entre as plantas de leiteiro (intraespecífica), que então, reduz a intensidade de competição com a cultura, segundo Chemale \& Fleck (1982).

Possíveis efeitos alelopáticos da aveia sobre o leiteiro, que não foram observados em termos de redução do número de infestantes ou taxa de emergência (Tabela 8), também tenderiam a reduzir a competição com a cultura, o que concorda com as observações de Almeida \& Rodrigues (1985), que em seu trabalho não constatou redução na germinação das sementes, no entanto reduzindo o comprimento da folha e da raiz. A quantidade de matéria seca de aveia estimada sobre a superfície do solo foi de $6 \mathrm{t} / \mathrm{ha}$.

O manejo com calcário, quando antecedido pelo pousio e com controle de presença do leiteiro, tendeu a resultar num aumento de $10,9 \%$ da produção de soja. A de 15,8 plantas $/ \mathrm{m}^{2}$ de leiteiro reduziu a produção em apenas $4,8 \%$, enquanto que, 31,0 plantas $/ \mathrm{m}^{2}$, na testemunha, reduziu em 14,5\%. Os resultados de Turkiewicz (1976) apoiam os resultados obtidos com soja, de favorecer a germinação e o vigor das sementes, podendo favorecer também o leiteiro. Este, no entanto, poderia ser desfavorecido em relação a uma menor competição com a cultura, mais responsiva ao uso de calcário.

\section{Efeitos gerais sobre a produção de soja}

$\mathrm{Na}$ Tabela 6, observa-se que as produtividades médias das interações na soja foram reduzidas significativamente na ausência de calcário e de herbicida, sendo isto atribuido principalmente à competição, mas não sendo influenciados pela presença ou não de aveia.

TABELA 6. Rendimentos de soja ( $\mathrm{kg} / \mathrm{ha}$ ) obtidos nos tratamentos de calcário, aveia e controle herbicida de leiteiro, na Embrapa-soja Londrina, PR.1997/98.

\begin{tabular}{cccc}
\hline Tratamento & Calcário & Aveia & Herbicida \\
\hline Com & $4.085 \mathrm{a}^{\mathrm{1}^{\prime}}$ & $3651 \mathrm{a}$ & $4.048 \mathrm{a}$ \\
Sem & $3.447 \mathrm{~b}$ & $3881 \mathrm{a}$ & $3.484 \mathrm{~b}$ \\
\hline $\mathrm{CV}(\%)=$ & 10,3 & 10,3 & 10,3 \\
$\mathrm{~F}=$ & 21,3 & 2,7 & 16,6 \\
$\mathrm{P}(\mathrm{F})=$ & 0,0003 & 0,1073 & 0,0008 \\
\hline
\end{tabular}

1/ Médias seguidas de mesmas letras minúsculas na vertical, não diferem significativamente entre si pelo teste de Tukey (P $\leq 0,05)$.

\section{LITERATURA CITADA}

ALLEM, A.C.; IRGANG, B.E. Euphorbiaceae: Tribo Euphorbiaeae. B. Inst. Ci. Nat. Univ. Fed. Rio G. Sul Sér. Bot., Porto Alegre, v.34, n.4, p.1-97, 1975.
ALMEIDA, F.S. A alelopatia e as plantas. IAPAR. Circular, 53. Londrina 60p. 1988.

ALMEIDA, F.S.; OLIVEIRA,V.F.; RODRIGUES, B.N. Influência da cobertura morta na intensidade e composição do 
complexo floristicoque se desenvolve nas culturas de verão. In: FUNDAÇÃ̃o INSTITUTO AGRONÔMICO DO PARANÁ. Resultados de Pesquisa da Área de Herbologia, Safra de 1983-84. Londrina, IAPAR, 1985. p.8-32.

ALMEIDA , F.S. de; RODRIGUES, B.N. Guia de herbicidas; contribuição para o uso adequado em plantio direto e convencional. Londrina, IAPAR 1985.

BAKER, H.G. Some aspects of natural history of seed banks. In: Lesk, M.A.; Parker, V.T. \& Simpson, R.L.(ed.) Ecology of soil seed banks. Academic Press. New York, p.921,1989 .

BANNON, J.S.; BAKER, J. B.; ROGERS, R.L. Germination of wild poinsettia (Euphorbia heterophylla). Weed Sci., v.26, p.221-225, 1978.

BUCHANAN, G.A.; HOVELAND, C.S.; HARRIS, M.C., Response of weeds to soil pH. Weed Sci., v.23, n.6 p.473-477, 1975.

BURGEOIS, T. The regional weed research project: aims and preliminary results. Cotton Fibres Trop. v.45, n.4, p.287-294, 1990.

BURR, I.W. \& FOSTER, L.A. A test for equality of variances. Mimeo Series $\mathrm{n}^{\circ} .282$. University of Purdue, West Lafayette, 1972. 26p.

CARMONA, R. Problemática e manejo de banco de sementes de invasoras em solos agrícolas. Planta Daninha, v.10, n.1/2,1992.

CERDEIRA, A.L.; VOLL, E. Germinação e emergência de amendoim-bravo (Euphorbia heterophylla L.), p.216-220. In: Resultados de Pesquisa de Soja 1979-80. Londrina Pr. EMBRAPA-CNPSo. 1980.

CHANCELLOR, R.J. Weed seed investigations, p.9-29, In: Advances in Research and Technology of seeds. Part.7 J:R:Thomson, International Seed Testing Association, Wageningen, 1982.

CONAB/DIDEM/GEAME. Soja area de produção e produtividade safras 96/97 e 97/98 Indicadores da Agropecuária, v.VII, n.6, p.45, 1998.

CORRÊA, A.R.; GODOY, H.; BERNARDES, L.R.M. Características climáticas de Londrina. $2^{\mathrm{a}}$ ed. (Circular IAPAR 5), Londrina PR IAPAR, 16p. 1982.

DAWSON, J.H.; Burns, v.f. Longevity of barnyardgrass, green foxtail, and yellow foxtail seeds in soil. Weed Sci., v.23, n.5, p.437-440, 1975.

KEELEY, P.E. \& THULLEN, R.J. Growth and competition of black nigthshade Solanum nigrum, and palmer amaranth Amaranthus palmeri with cotton Gossypium hirsutum. Weed Sci., v.37, n.3, p.326-334, 1989.

KIMBER, R.W.L. Phytotoxicity from plant residues. I The influence of rotted wheat straw on seedling growth. Aust. J. Agric. Res., n.18, p.361-374, 1967.

KIMBER, R.W.L. Phytotoxicity from plant residues I The influence of rotted wheat straw on seedling growth. Australian J. Agric. Res., n. 18 p.543-555, 1973.

KISSMANN K.G. Euphorbia heterophylla L., . (BASF Boletim Técnico), BASF, 7p. SP. São Paulo, 1980. 
LEGUIZAMÓN, E.S. Seed surviral and partterns of seedling emergence in Sorghum halepense L. Pers. Weed Res., v.26, n.6, p.1-7,1986.

LIEBL, R.A.; WORSHAM, A.D. Tillagege and mulch effects on morningglory (Ipomoea spp.) and certaim other weed species. Proc. Weed Sci. Soc., v.43,p405-414, 1983.

LORENZI, H. Plantas daninhas do Brasil: terrestres, aquáticas, parasitas, tóxicas e medicinais. 2.ed., Nova Odessa, SP.: Editora Plantarum, 1991. 441p.

MACHADO-NETO, \& J. PITELLI, R.A. Profundidade de semeadura na emergência de amendoim-bravo. Pesqui. Agropec. Bras., v.23, n.11, p.1203-1208, 1980.

MCCALLA, T.M.; NORSTADT, F. A. Toxicity problems in mulch tillage. Agric. Environ., n.1, p.153-174, 1974.

NORSTADT, F. A., MCCALLA, T.M., Microbial population in stubble-mulched soil. Soil Sci., n.107, p.188-193, 1968.

OSMAN, M. A.; RAJU, P.S.; PEACOCK, J.M. The effect of soil temperature, moisture and nitrogen on Striga asiatica L. Kuntse seed germination, viability and emergence on sorghum Sorghum bicolor (L.)(Moench) roots under field conditions. Plant and Soils, v.131, n.2, p. 265-273, 1991.

PANETTA, F.D.; GILBEY, D.J.; D'ANTUONO, M.F. Survival and fecundity of wild radish (Raphanus raphanistrum L). plants in relation to cropping, time of emergence and chemical control. Australian Journal of Agricultural Research, v.39, n.3. p.385$397,1988$.
PARENTE, R.C.P. Aspectos da análise de resíduos. Piracicaba. Tese de mestrado. ESALQ/USP, 1984. 118p.

PARKER, V.T.; SIMPSON, R.L.; LECK, M.A. Pattern and process in the dynamics of seed banks.In:Leck,M.A.; Parker, V.T.\& Simpson, R.L. (ed.).Ecology of Soil Seed Banks. Academic Press, NewYork 1989, p.367-384.

PETRELLI, G. Observação sobre a biologia do leiteiro (Euphorbia heterophylla L.) no Estado do Rio Grande do Sul, Brasil, Pelotas. Embrapa, UEPAE-Pelotas, 1983 (Comunicado Técnico. Outubro 1983, v.11, n.6).

PROBERT, R.J.; SMITH, M.R.D.; BIRCH, P. Germination responses to light and alternating temperatures in European populations of dactylis glomerata L. I. Variability in relation to origen. New Phytol., v.99, n.305-316, 1985.

PURVIS, C.E.; JESSOP, R.S., LOVETT, J.V. Selective regulation end growth of annual weeds by grop residues. Weed Res., v.25, p.415-421, 1985.

STEINSIEK, J.W.; OLIVER,.R; COLLINS, F.C. Allelopathic potencial of wheat (Triiticum aestivum) straw on selected weed species. Weed Sci., v.30, p.495-457, 1982.

SHAPIRO, S.S. \& WILK, M.B. An analysis of variance test for normality. Biometrika, v.52, p.559-661, 1965.

TAYLORSON, R.B. The role of seed dormancy and germination in devising weed control methods. In: World Soybean Research Conference. mar, 1985. Ames. Proceedings Boulder Westernwiew Press, p.1097-1104. 1985. 
TUKEY Jr., H.B. The leaching of substances from plants. Am. Rev. P. Physiol., n.21, p.305, 1970.

TUKEY, J.W. One degree of freedom for nonadditivity. Biometrics, v.5, p.232-242, 1949.

TURKIEWICZ, L. Efeito da calagem e adubação fosfatada sobre a germinação e o vigor de sementes de soja. Piracicaba: USP, 1976. Escola Superior de Agricultura "Luiz de Queiroz". Univer. do Estado de São Paulo, 1976. 135 p. (Dissertação de Mestrado).

VIEIRA, M.J. Propriedades físicas do solo. In: Plantio direto no Estado do Paraná. Londrina, IAPAR, 1981, p. 19-32. (CIRCULAR IAPAR, 23). 